\title{
Congenital hypothyroidism: optimal management in the light of 15 years' experience of screening
}

\author{
D B Grant
}

The task of defining 'optimal management' of any condition presents a considerable challenge in today's climate of 'consensus management' and 'best practice', particularly in congenital hypothyroidism where there is still room for debate about the most appropriate dose of thyroxine needed in early infancy. In this paper I will describe my own approach since screening for congenital hypothyroidism was introduced in $1978,{ }^{1}$ but I will also indicate those areas in which there is still some controversy.

Before introduction of screening, the major complications of late treated congenital hypothyroidism were impaired intelligence and a range of abnormalities of neurological function, particularly with respect to coordination. ${ }^{2}$ At that time there was already evidence that outcome for intelligence was best in the cases who had been started on treatment within a few weeks of birth. ${ }^{23}$ Since the introduction of screening my practice has been based on the belief that adequate treatment during infancy, particularly during the first year of life, is very important to obtain the best possible outcome.

\section{Telling parents about an abnormal screening test for congenital hypothyroidism}

Almost all parents are shocked to learn that their new baby has a positive screening test result and informing them about this has been one of the more difficult areas to get right. When screening started families were usually told about a positive result by a midwife or nurse, who sometimes gave an inappropriately gloomy description of cretinism with severe mental retardation. General practitioners or community paediatricians are now asked to inform the family and they are given a much more balanced account of the importance of further investigation and treatment.

Medical Unit, Division
of Clinical Science,
Institute of Child
Health,
Guilford Street,
London
WC1N 1EH
Correspondence to:
Dr Grant.

visit to hospital is probably one of the most stressful times they have ever experienced. Before being told about the positive screening result, most mothers had not considered their

\section{First clinical assessment}

\section{CLINICAL AND BIOCHEMICAL ASSESSMENT}

For almost all families with a child detected by baby abnormal in any way and they may have many questions and worries that are difficult to express, particularly in the setting of a busy outpatient clinic. Their most important question on the long term outcome may be particularly difficult to deal with at the first visit as a considered prognosis based on the severity of their child's hypothyroidism may need to await the pretreatment plasma thyroxine and thyroid stimulating hormone (TSH) results.

Whenever possible, we try to see new cases as urgent day cases so that time is available for discussion of the child's overall management plan and parents are given a factsheet to take home and show to other members of the family. After clinical assessment, looking for features of congenital hypothyroidism and for other congenital malformations that are present in about $7 \%$ of cases, ${ }^{4}$ blood is taken for estimation of plasma TSH and thyroxine (either as total thyroxine or free thyroxine) to confirm or refute the diagnosis. During this visit it is essential to obtain as much diagnostic information as possible and estimation of either TSH or thyroxine alone is not adequate. While a raised $\mathrm{TSH}$ indicates a likely diagnosis of congenital hypothyroidism, it does not provide a reliable guide to the severity of the disorder; plasma thyroxine provides information on the severity of congenital hypothyroidism but as some children may have near normal (or within normal) thyroxine values the results can be difficult to evaluate on their own.

\section{ISOTOPE SCAN OF THYROID}

This is carried out whenever possible before starting treatment but if necessary can be done after a few days of treatment. We chose to use technetium-99m $\left({ }^{99 m} \mathrm{Tc}\right)$ because of its ready availability. The isotope scan usually gives clear cut diagnostic information and allows the family to be given an explanation of the nature of their child's disorder, particularly if an ectopic gland is seen or there is absent or reduced isotope uptake in the neck because of agenesis or hypoplasia of the thyroid. These findings indicate a general diagnosis of 'thyroid dysgenesis', which has a low risk of recurrence (probably around $1: 100$ ) but is of as yet unknown pathogenesis.

By showing normally sited thyoid tissue, an isotope scan with ${ }^{99 \mathrm{~m}} \mathrm{Tc}$ also allows 
identification of an inherited defect of thyroxine biosynthesis that generally carries a 1:4 risk of recurrence. This isotope, however, is not suitable for the perchlorate discharge test that is abnormal in Pendred's syndrome (goitre due to impaired iodide organification associated with deafness). In cases with a normally sited gland, we still do not try to identify the type of biosynthetic defect but specialised laboratory methods for doing this are now well established. ${ }^{5}$

Very occasionally the ${ }^{99 m}$ Tc scan gives a misleading result. Over the last 15 years we have encountered a small number of cases who have had no isotope uptake in the neck but who were subsequently shown to have normal thyroid function at the time of the scan. While the cause is not clear, the appearance of 'agenesis' using ${ }^{99 m}$ Tc must be viewed with some suspicion until the diagnosis is confirmed by the results for plasma TSH and thyroxine.

Many radiology departments would have little difficulty in carrying out an isotope scan of the thyroid in a small baby but units with little paediatric experience might find this more of a problem. In addition, some might argue that an isotope scan is not necessary before deciding on treatment and that the small radiation dose cannot be justified. For the reasons given above, we do not subscribe to this view.

ULTRASOUND SCAN OF THE THYROID

We have found ultrasound of the neck of limited value in small infants with congenital hypothyroidism, largely because of difficulty in identifying ectopic thyroid tissue. ${ }^{6}$

\section{RADIOGRAPHY OF THE KNEE}

Demonstration of absent epiphyses at the knee was once the most common test for congenital hypothyroidism. Like others, ${ }^{7-9}$ we continued this practice for many years as we thought that the degree of bone age delay might be of prognostic value with respect to the outcome for intelligence. Analysis of the IQ score at 5 years in 63 of our patients showed, however, that the knee radiograph did not predict outcome as clearly as pretreatment plasma thyroxine concentration (J J Rangasami and D B Grant, unpublished) and we have now abandoned this investigation. After treatment has been started, serial radiography of the wrist and hand for estimation of bone age is of little value and we do not carry this out on a routine basis.

\section{STARTING TREATMENT}

After discussion with the family, treatment with L-thyroxine is started at the first visit and before the plasma TSH and thyroxine results are known, and we have used a standard starting dose of $25 \mu \mathrm{g} /$ day. This dose of thyroxine is lower than the $10-15 \mu \mathrm{g} / \mathrm{kg} /$ day recommended by the American Academy of Pediatrics in their guidelines on screening for congenital hypothyroidism. ${ }^{10}$ The question of thyroxine dosage in early infancy is considered again below.

A suitable suspension/solution of thyroxine is not available in the UK and parents are instructed to give a $25 \mu \mathrm{g}$ tablet crushed in milk or water using a teaspoon: parents are asked to repeat the dose if the baby vomits or regurgitates the medication.

\section{First follow up assessment}

COUNSELLING THE FAMILY

Whenever possible the patient is seen again after two weeks to review the pretreatment biochemical results and discuss their significance with the family. In most cases, the initial TSH results are clearly abnormal and the plasma thyroxine concentrations are in keeping with the findings on the isotope scan, leaving no room for doubt that the diagnosis of congenital hypothyroidism is correct and that lifelong treatment will be needed.

In the few cases with false positive screening tests, the pretreatment TSH and thyroxine will be completely normal and the family can be reassured that further treatment and hospital follow up are not required. In some cases, however, a mild increase in TSH with normal thyroxine are found and this can lead to considerable anxiety, particularly if parents sense that there is uncertainty as to whether or not their child needs to be treated. Such results can occur in a child with a partial thyroxine biosynthetic defect or a large ectopic gland (or a hypoplastic normally sited gland) that can maintain plasma thyroxine concentrations in the normal range under increased TSH drive. In these cases I have usually started treatment with thyroxine because of the risk of future thyroid failure with progressive onset of hypothyroidism. Mild hyperthyrotropinaemia has also been reported in a few families where it appears to be an inherited characteristic. In some cases extensive investigation does not elucidate the cause of the abnormal TSH concentrations and an empirical decision has to be made as to whether treatment is needed. We have tended to keep such cases under review, checking growth and thyroid status for up to three years to confirm that clinical and biochemical features of clear cut hypothyroidism do not develop.

\section{OUTCOME FOR INTELLIGENCE}

During the early years of screening I believed I could take an optimistic outlook with respect to outcome for intelligence and early follow up results seemed to support this approach, many studies showing no significant differences between the children with congenital hypothyroidism and healthy controls. ${ }^{71-14}$ Further analysis of the results suggested that outcome may not be quite so good in infants with severe hypothyroidism, as judged by low pretreatment plasma thyroxine concentration or retarded bone age. ${ }^{8915-17}$ Our own results in a large national cohort of children with congenital hypothyroidism who were tested at 5 years shows that those with low pretreatment 
thyroxine concentrations (below $42 \mathrm{nmol} / \mathrm{l}$ ) had a mean deficit of around 10 IQ points compared with controls; on average, subjects with pretreatment thyroxine concentrations over $42 \mathrm{nmol} / \mathrm{l}$ did as well as healthy children. ${ }^{18}$

In the light of these findings, we now counsel that children with very low pretreatment thyroxine concentrations may be rather less intelligent than expected for their family backgrounds but that they will almost certainly be able to attend normal school and live healthy, useful lives as adults. This view, however, is not in line with results from the US where the New England Congenital Hypothyroidism Collaborative have reported completely normal IQ scores and school attainment up to the age of 9 years, ${ }^{11} 1920$ except in cases with early clinical features of severe congenital hypothyroidism or if compliance with treatment has been poor. These results have been taken to indicate that the effects of prenatal hypothyroidism can be completely reversed by early treatment and it has been suggested that the normal outcome in the New England study may be related to the use of a higher dose of thyroxine. ${ }^{21}$ Very recently, Dubuis et al in Quebec reported that 10 infants with severe hypothyroidism treated with a mean daily dose of $11.5 \mu \mathrm{g} / \mathrm{kg}$ thyroxine (mean IQ 108) did better than similar cases treated with 6-8 $\mu \mathrm{g} / \mathrm{kg} /$ day (mean IQ 98).22 Further evidence of the importance of treatment during the first year comes from Norway where Heyerdahl and her colleagues found that four children with mean plasma thyroxine concentrations below $129 \mathrm{nmol} / \mathrm{l}$ in the first year had low IQ scores at 6 years. ${ }^{23}$ The small number of patients in these latter reports, however, preclude any definite conclusions. In our own study we were unable to show any relationship between the starting dose of thyroxine and outcome at 5 years, ${ }^{18}$ and my personal view is that the starting dose of thyroxine probably does not have a significant effect on outcome, providing that dosage is reviewed (and when necessary, adjusted) fairly frequently during the first year of life.

While early treatment of congenital hypothyroidism does not completely eliminate difficulties with coordination, ${ }^{17}$ these are much less marked than those seen before the start of screening. ${ }^{2}$ Nevertheless, parents need to be aware that their child may have some minor difficulties with balance or rapid fine manipulation so that these can be recognised and not allowed to cause problems at school.

ADVICE ON LONG TERM MEDICATION

The plasma TSH and thyroxine results taken at the second visit will give guidance on whether the starting dose of thyroxine needs to be changed. If plasma thyroxine is near or below the lower limit of normal and TSH remains raised we would probably increase the dose of thyroxine to $37.5 \mu \mathrm{g} /$ day and emphasise the importance of close follow up.
Parents may need to be reassured that lifelong treatment with thyroxine at the correct dose does not have any side effects and will not interfere with other medications that may be needed in the future; that the dose of thyroxine will increase as their child grows, so that around $50-62.5 \mu \mathrm{g} /$ day will probably be needed at 1 year of age and $100 \mu \mathrm{g} /$ day may be needed between the ages of 3 and 5 years; and that as a result of adequate treatment growth, puberty, future fertility, and life expectancy will be normal. Parents also need to know that poor compliance, particularly in early infancy, may cancel the benefits of screening and early treatment.

\section{Further follow up assessments}

BIOCHEMICAL MONITORING AND THYROXINE DOSAGE

In general, we have seen children with congenital hypothyroidism at six to eight week intervals in the first year. Plasma TSH and thyroxine are rechecked about eight weeks after starting treatment and then usually two or three more times during the first year, aiming to keep plasma TSH close to normal and plasma thyroxine in the upper part of the normal range. After the first birthday follow up visits become less frequent, usually every three to four months for the next year, six monthly between the ages of 2 and 5 years, and then once or twice yearly until growth is complete. Frequent assay of TSH and thyroxine is probably less important after the first birthday, particularly when normal growth and good developmental progress point to adequate treatment. It should be noted, however, that the American Academy of Pediatrics recommends more frequent estimation of plasma TSH and thyroxine, suggesting that tests are carried out every one to two months in the first year and every two to three months until the age to 3 years. ${ }^{10}$

When growth and physical development are complete, further change in thyroxine dose becomes unlikely and most of our patients are discharged to the care of their general practitioner, usually on $100-200 \mu \mathrm{g}$ thyroxine given once daily.

Persistently high TSH concentrations are common in congenital hypothyroidism despite treatment and plasma thyroxine needs to be kept in the upper part of the normal range to achieve normal TSH values. ${ }^{24}$ When TSH remains raised after the first weeks of treatment, increasing the dose of thyroxine almost invariably results in normalisation of TSH. If this does not occur, poor treatment compliance is the likely explanation. In older children it is far from certain whether a slight increase of TSH on treatment is of clinical importance, particularly if growth and developmental progress are completely normal and plasma thyroxine is well within the normal range.

Generally difficult behaviour has been described in children with congenital hypothyroidism and this has been associated with high plasma thyroxine concentrations during 
the first year. ${ }^{25}$ Parents sometimes report that their child tends to be overactive and show poor concentration at school, and a few have said that their children are easier to manage if the dose of thyroxine is reduced to a concentration that is associated with increased TSH. In such cases, I have sometimes rather reluctantly agreed to the use of a lower dose of thyroxine with a modest increase in plasma TSH, provided plasma thyroxine is satisfactory and the child's growth and development are normal.

Plasma thyroxine concentrations above the normal range are found in some children on apparently appropriate doses of thyroxine: cutting the dose results in an abnormal rise in TSH. If these high concentrations of thyroxine are not associated with symptoms of overtreatment I have tended to ignore the laboratory results. Introduction of highly sensitive assays for TSH, however, has made it possible to detect TSH over suppression and it may become clear that in some of these cases the high plasma thyroxine is the result of overtreatment.

\section{ARRANGING A TRIAL OFF TREATMENT}

While the pretreatment tests may leave no doubt about the diagnosis of congenital hypothyroidism by showing either low/ low-normal thyroxine values in a child with an ectopic thyroid or undetectable thyroxine in a case with thyroid agenesis, in cases with a normally sited thyroid and a thyroxine biosynthetic defect the thyroxine concentrations may range from undetectable to low-normal, depending on the severity of the enzyme defect, and in some cases transient hypothyroidism is a possibility. Transient hypothyroidism is also more likely if the baby was born preterm or had neonatal problems, or was born to a mother with thyroid disease. Maternal iodine deficiency and exposure of the baby to high concentrations of iodine either before or soon after birth can also be associated with transient hypothyroidism.

In these circumstances we usually arrange a trial off treatment at around 18-24 months of age. To keep the time without treatment to a minimum, triiodothyronine $(10 \mu \mathrm{g}$ twice a day) is given for three weeks in place of the usual dose of thyroxine. Treatment is then stopped and blood is taken for $\mathrm{TSH}$ and thyroxine assay after one week; the previous dose of thyroxine is restarted while awaiting the biochemical results. This rather complex procedure may not be strictly necessary, 1026 but most parents are reassured to know that their child will be without treatment for only one week. It is also reassuring for them to know that the diagnosis has been fully confirmed and that lifelong treatment will be needed.

Withdrawal of treatment is not usually needed in patients with clinical signs of hypothyroidism and very low thyroxine concentrations at diagnosis, or in children with ectopic thyroids who are unlikely to be able to come off treatment, ${ }^{27}$ and is not indicated in patients who have shown high TSH concentrations on treatment after the age of 6 months.

\section{Conclusion}

As in any chronic medical condition, management of a child with congenital hypothyroidism requires a well planned strategy that is shared with the family; it also needs attention to detail and continuity of medical support to ensure the best results. While there are still some unanswered questions, particularly about the dose of thyroxine in early infancy, as a result of screening and early treatment most children with congenital hypothyroidism can be expected to grow up in full health with normal intelligence.

A copy of our factsheet on congenital hypothyroidism can be obtained from Mrs J L Hickey, The British Thyroid Association, PO Box HP22, Leeds LS6 3RT.

1 Hulse JA, Grant DB, Clayton BE, et al. Population screening for congenital hypothyroidism $B M 71980 ; 280 ; 675-8$. 2 Macfaul R, Dorner S, Brett EM, Grant DB. Neurological abnormalities in patients treated for hypothyroidism from early life. Arch Dis Child 1978; 53: 611-9.

3 Klein AH, Meltzer S, Kenny FM. Improved prognosis in congenital hypothyroidism treated before age three months. $\mathcal{F}$ Pediatr 1972; 81: 912-5.

4 Grant DB, Smith I. Survey of neonatal screening for primary hypothyroidism in England, Wales, and Northern Ireland 1982-4. BMF 1988; 296: 1355-8.

5 Grüters A, Funke R, Krude H, Meinhold H. Etiological grouping of permanent congenital hypothyroidism with thyroid gland in situ. Horm Res 1994; 41: 3-9.

6 DeBruyn $\mathrm{R}, \mathrm{Ng}$ WK, Taylor J, et al. Neonatal hypothyroidism: comparison of radioisotope and ultrasound imaging in 54 cases. Acta Paediatr Scand 1990; 79: 1194-8.

7 Rochiccioli P, Dutau G, Roge B, Petrus M, Augier D, Enjaume C. Le depistage neonatal de l'hypothyroidie en
France. fournal de Génétique Humaine 1981; 29: 13-22.

8 Glorieux J, Dussault JH, Morisette J, et al. Follow up at ages 5 and 7 years on mental development in children with hypothyroidism detected by Quebec screening program Pediatr 1985; 107: 913-5.

9 Rovet J, Ehrlich R, Sorbara D. Intellectal outcome in children with fetal hypothyroidism. F Pediatr 1987; 110: 700-4

10 LaFranchi S, Dussault JH, Fisher DA, et al. Newborn screening for congenital hypothyroidism: recommended guidelines. Pediatrics 1993; 91: 1203-9.

11 New England Congenital Hypothyroidism Collaborative Effects of neonatal screening for hypothyroidism: prevention of mental retardation by treatment before clinical manifestations. Lancet 1981; ii: 1095-8.

12 Illig R, Largeo RH, Weber M, et al. Sixty children with congenital hypothyroidism detected by neonatal screening: Mental development at 1, 4, and 7 years: a longitudinal study. Acta Endocrinol (Copenh) 1986; 279 (suppl): study. $A$. 33 .

13 Komianou F, Makaronis G, Lambadaridis J, et al. Psychomotor development in congenital hypothyroidism: Psychomotor development in congenital hypothyroidism: the Gre

14 Ilicki A, Larsson A. Psychological development at 7 years of age in children with congenital hypothyroidism: timing and dosage of initial treatment. Acta Paediatr Scand 1991 80: 199-204.

15 Virtanen M, Santavouri P, Hirvonen E, Perheentupa J Multivariate analysis of psychomotor development in congenital hypothyroidism. Acta Paediatr Scand 1989; 78 405-11.

16 Toublanc JE, Rives S, Acosta A, Chicaud J. Le développment psychomoteur et intellectuel chez 52 enfants atteints d'hypothyroïdie congénitale dépistée à la naisance. Arch Fr Pediatr 1990; 47: 191-5.

17 Fuggle PW, Grant DB, Smith I, Murphy G. Intelligence, motor skills and behaviour at 5 years in early-treated con-

18 Tillotson SL, Fuggle PW, Smith I, Ades AE, Grant DB. Relation between biochemical severity and intelligence in
early treated congenital hypothyroidism: a threshold early treated congenital hyp $B M \mathcal{1}$ 1994; 309: 440-5.

19 New England Congenital Hypothyroidism Collaborative. Neonatal hypothyroidism screening: status of patients at 6 years of age. F Pediatr 1985; 107: 915-9.

20 New England Congenital Hypothyroidism Collaborative. Elementary school performance of children with congeniElementary school performance of children with

21 Mitchell ML, Hermos RJ, Frederick DL, Klein RZ. Problems in the management of patients with infantile Problems in the management of patients with infantile
hypothyroidism. In: Delange F, Fisher DA, Glinoer D, hypothyroidism. In: Delange F, Fisher DA, Glinoer D, eds. Research in congenital hypo
Plenum Press, 1989: 237-44. 
22 Dubuis J-M, Richer F, Glorieux J, Deal C, Dussault JH. Should all patients with congenital hypothyroidism $(\mathrm{CH})$ be treated with $10-15 \mu \mathrm{g} / \mathrm{kg}$.day levothyroxine (T4)? Pediatr Res 1994; 35 (4/part 2): 98 A

23 Heyerdahl S, Kase BF, Lie SO. Intellectual development in children with congenital hypothyroidism in relation to recommended thyroxine treatment. $f$ Pediatr $1991 ; 118$ 850-7.

24 Grant DB, Fuggle PW, Smith I. Increased plasma thyroid stimulating hormone in treated congenital hypothystimulating hormone in treated conge
roidism. Arch Dis Child 1993; 69: 555-8.
25 Rovet JF, Ehrlich RM, Sorbara D-L. The effect of thyroid hormone level on temperament in infants with congenital hypothyroidism detected by screening of neonates. f Pediatr 1989; 114: 63-8.

26 Davy T, Daneman D, Walfish PG, Ehrlich RM. Congenital hypothyroidism: effect of stopping treatment at 3 years of age. Am $\mathcal{F}$ Dis Child 1985; 139: 1028-30.

27 Grant DB, Hulse JA, Jackson DB, Leung SP, Ng WK Ectopic thyroid: residual function after withdrawal of treatment in infancy and later childhood. Acta Paediatr treatment in infancy and $1989 ; 78:$ 889-92. 